\title{
Preventing ophthalmia neonatorum
}

\author{
Dorothy L Moore, Noni E MacDonald; Canadian Paediatric Society, \\ Infectious Diseases and Immunization Committee
}

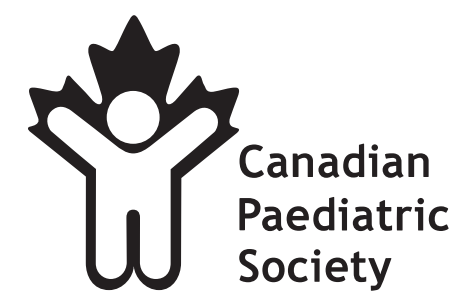

DL Mooore, NE MacDonald; Canadian Paediatric Society, Infectious Diseases and Immunization Committee. Preventing ophthalmia neonatorum. Paediatr Child Health 2015;20(2):93-96.

The use of silver nitrate as prophylaxis for neonatal ophthalmia was instituted in the late 1800 s to prevent the devastating effects of neonatal ocular infection with Neisseria gonorrhoeae. At that time - during the preantibiotic era - many countries made such prophylaxis mandatory by law. Today, neonatal gonococcal ophthalmia is rare in Canada, but ocular prophylaxis for this condition remains mandatory in some provinces/ territories. Silver nitrate drops are no longer available and erythromycin, the only ophthalmic antibiotic eye ointment currently available for use in newborns, is of questionable efficacy. Ocular prophylaxis is not effective in preventing chlamydial conjunctivitis. Applying medication to the eyes of newborns may result in mild eye irritation and has been perceived by some parents as interfering with mother-infant bonding. Physicians caring for newborns should advocate for rescinding mandatory ocular prophylaxis laws. More effective means of preventing ophthalmia neonatorum include screening all pregnant women for gonorrhea and chlamydia infection, and treatment and follow-up of those found to be infected. Mothers who were not screened should be tested at delivery. Infants of mothers with untreated gonococcal infection at delivery should receive ceftriaxone. Infants exposed to chlamydia at delivery should be followed closely for signs of infection.

Key Words: Chlamydia; Gonococcus; Neonatal ophthalmia; Prophylaxis; Screening in pregnancy; STIs

$T^{1}$ he present statement replaces a statement on neonatal ophthalmia published in 2002 by the Canadian Paediatric Society's Infectious Diseases and Immunization Committee.(1) This update is indicated because in Canada, the epidemiology and antibiotic susceptibility of Neisseria gonorrhoeae, as well as the availability of products for prophylaxis, have all changed, raising concerns about the utility of the previously recommended strategy.

Neonatal ophthalmia, a relatively common illness, is defined as conjunctivitis occurring within the first four weeks of life.(2) Originally, this term only referred to cases caused by $N$ gonorrhoeae, but the term currently encompasses any conjunctivitis in this age group. $N$ gonorrhoeae now accounts for $<1 \%$ of reported cases of neonatal ophthalmia in the United States, while that due to Chlamydia trachomatis ranges from 2\% to $40 \%$. Other bacteria such as Staphylococcus species, Streptococcus species, Haemophilus species and other Gram-negative bacterial species account for $30 \%$ to $50 \%$ of cases. (2) Much less commonly, neonatal conjunctivitis is caused by viral infections (herpes simplex, adenovirus, enteroviruses). Infectious conjunctivitis must be distinguished from eye discharge secondary to blocked tear ducts and from conjunctivitis due to exposure to chemical or other irritants.

In most instances, neonatal ophthalmia is a mild illness. The exception is ophthalmia due to infection with $N$ gonorrhoeae.(2) Without

\section{La prévention de la conjonctivite néonatale}

Le nitrate d'argent a commencé à être utilisé en prophylaxie à la fin des années 1800 pour prévenir les effets dévastateurs de l'infection oculaire à Neisseria gonorrhoeae du nouveau-né. À cette époque où les antibiotiques n'existaient pas, cette prophylaxie avait force de loi dans de nombreux pays. De nos jours, la conjonctivite gonococcique du nouveau-né est rare au Canada, mais la prophylaxie oculaire demeure obligatoire dans certaines provinces et certains territoires. Les gouttes de nitrate d'argent ne sont plus en marché, tandis que l'efficacité de l'érythromycine, le seul onguent antibiotique actuellement offert pour les nouveau-nés, est douteuse. La prophylaxie oculaire ne prévient pas la conjonctivite à Chlamydia avec efficacité. L'application de médicaments dans les yeux des nouveau-nés peut provoquer une irritation oculaire bénigne. Pour certains parents, cette pratique nuit à l'attachement entre la mère et son nourrisson. Les médecins qui s'occupent de nouveau-nés devraient plaider pour la suppression des lois qui obligent la prophylaxie oculaire. Parmi les moyens plus efficaces de prévenir la conjonctivite néonatale, soulignons le dépistage de la gonorrhée et de la Chlamydia chez toutes les femmes enceintes et le traitement et le suivi de celles qui sont infectées. Les femmes qui n'ont pas été soumises au dépistage devraient l'être à l'accouchement. Les nourrissons de mères chez qui on décèle, à l'accouchement, une gonococcie non traitée devraient recevoir de la ceftriaxone. Ceux exposés à la Chlamydia lors de l'accouchement devraient faire l'objet d'un suivi étroit pour déceler tout signe d'infection.

preventive measures, gonococcal ophthalmia occurs in 30\% to $50 \%$ of infants exposed during delivery(3-5) and may progress quickly to corneal ulceration, perforation of the globe and permanent visual impairment.(6) Infants at increased risk for gonococcal ophthalmia are those whose mothers are at risk for sexually transmitted infections (STIs).(7)

Historically, the purpose of prophylaxis for neonatal ophthalmia was to prevent devastating neonatal eye infection due to $\mathrm{N}$ gonorrhoeae. Silver nitrate prophylaxis against $N$ gonorrhoeae ophthalmia neonatorum, first used by Dr Carl Credé in 1880,(6) was a significant preventive medicine triumph at a time when there was no effective treatment available for gonorrhea. Nevertheless, silver nitrate was not a perfect agent because it caused transient chemical conjunctivitis in $50 \%$ to $90 \%$ of infants.(8) Also, some parents were concerned that the practice could interfere with mother-infant bonding.(9) Silver nitrate eye drops are no longer available in Canada. Tetracycline and erythromycin ointments have been considered to be acceptable alternatives for preventing gonococcal ophthalmia. $(2,10)$ However, $N$ gonorrhoeae strains isolated in Canada in 2012 showed considerable resistance to these agents, with tetracycline at $30 \%$ and erythromycin at $23 \%$.(11) Whether this resistance can be overcome by the high local antibiotic levels achieved by topical 
application is unknown, and there are no recent studies of the efficacy of ophthalmia prophylaxis with these agents.

In Canada, erythromycin has been the only antibiotic eye ointment available for use in neonates since tetracycline ophthalmic ointment became unavailable. Povidone-iodine has been considered for prophylaxis, (12) but this agent may not be effective $(13,14)$ and has been associated with a $5 \%$ rate of chemical conjunctivitis.(15) Gentamicin ointment was used for newborn ocular prophylaxis during a shortage of erythromycin ointment in the United States in 2009, but resulted in reports of severe ocular reactions. $(16,17)$ Other ophthalmic antibiotic preparations have not been evaluated in newborns. Therefore, it is questionable whether universal ocular prophylaxis for neonatal gonococcal ophthalmia remains an effective option in Canada. Of note, universal ocular prophylaxis was abandoned decades ago in several high-income countries including Denmark, Norway, Sweden and the United Kingdom. One study from the United Kingdom showed that this change did not increase the rate of blindness due to gonococcal ophthalmia. (18) However, the Canadian Medical Protective Association established that in 2013, neonatal ocular prophylaxis was required by law in Alberta, British Columbia, Ontario, Prince Edward Island and Quebec. In British Columbia, prophylaxis may be waived if a parent makes a written request. In New Brunswick, the law requiring prophylaxis was repealed in 2009. No current legislation was found for the remaining provinces and territories. $(19,20)$

Infants born to women with untreated chlamydia infection at delivery have a $50 \%$ risk of acquiring chlamydia, a $30 \%$ to $50 \%$ risk of developing neonatal conjunctivitis and a $10 \%$ to $20 \%$ risk of developing chlamydia pneumonia.(21) Topical ocular prophylaxis does not prevent transmission from mother to infant, does not reliably prevent neonatal conjunctivitis and does not prevent pneumonia.(10,22-26) Oral erythromycin prophylaxis of infants born to untreated mothers has been used in the past but has not been recommended since the association between erythromycin and pyloric stenosis was recognized.(27) Routine prenatal screening for C trachomatis and treatment of identified infections during pregnancy is the preferred option for preventing neonatal conjunctivitis and other infections in newborns caused by this organism. Close clinical follow-up of exposed infants is recommended.(2,28) The Public Health Agency of Canada recommends testing conjunctival and nasopharyngeal secretions of symptomatic infants and treating those who show positive results.(28)

A recent meta-analysis concluded that evidence from randomized and quasirandomized trials regarding the efficacy of prophylactic agents used to prevent gonococcal and chlamydia conjunctivitis was not of high quality. Moreover, all of the agents reviewed had clinically significant failure rates.(18)

Rates of neonatal ophthalmia caused by $N$ gonorrhoeae and C trachomatis declined significantly in North America through the 1980s due to the decreased prevalence of these infections in the general population, and the institution of routine prenatal screening and treatment of these STIs in pregnancy. $(18,19)$ In the United States in 2002, the rate of neonatal ophthalmia was 8.5 per 100,000 births.(18) National surveillance of neonatal ophthalmia was discontinued in Canada in 2000 because of low incidence.(29) Current rates of infection can be estimated from reported cases of chlamydia and gonorrhea in infants $<1$ year of age, for whom the average national rate between 2000 and 2011 was six per 100,000 for chlamydia infection and 0.5 per 100,000 for gonorrhea.(30) In Ontario, the combined rate of chlamydia and gonococcal ophthalmia in 2004 was 4.5 per 100,000.(18) There were no reported cases of neonatal gonococcal ophthalmia in Alberta between 2005 and 2013, but rates of chlamydial ophthalmia ranged from 0 to 12.2 per 100,000 per year, with a reported rate of 7.5 per 100,000 in 2013.(31) In areas of the world where prenatal screening and treatment are not available and prevalence of gonococcal infections is high, vision loss from neonatal gonococcal ophthalmia continues to occur and ocular prophylaxis with silver nitrate continues to be an important and cost-effective intervention. $(4,32)$
If ocular prophylaxis must be given to comply with provincial/ territorial regulations, $0.5 \%$ erythromycin base can be used and may be effective in some cases, depending on the antibiotic sensitivity of circulating strains. Povidone-iodine or gentamicin ointment should not be used because of high rates of adverse topical effects. $(2,7)$ To prevent potential cross-contamination, single-use tubes of erythromycin are used. Before administration, each eyelid is wiped gently with sterile cotton to remove foreign matter and to permit adequate eversion of the lower lid. A line of antibiotic ointment, sufficiently long to cover the entire lower conjunctival area, is placed in each lower conjunctival sac, taking care to prevent injury to the eye or the eyelid from the tip of the tube. The closed eyelids are massaged gently to help spread the ointment. After $1 \mathrm{~min}$, excess ointment is gently wiped from the eyelids and surrounding skin with sterile cotton.

\section{RECOMMENDATIONS}

To prevent neonatal ophthalmia caused by $N$ gonorrhoeae and $C$ trachomatis, the Canadian Paediatric Society recommends the following:

\section{Neonatal ocular prophylaxis:}

- Neonatal ocular prophylaxis with erythromycin, the only agent currently available in Canada for this purpose, may no longer be useful and, therefore, should not be routinely recommended.

- Paediatricians and other physicians caring for newborns, along with midwives and other health care providers, should become familiar with local legal requirements concerning ocular prophylaxis.

- Paediatricians and other physicians caring for newborns should advocate to rescind ocular prophylaxis regulations in jurisdictions in which this is still legally mandated.

- Jurisdictions in which ocular prophylaxis is still mandated should assess their current rates of neonatal ophthalmia and consider other, more effective preventive strategies, as outlined below.

\section{Screening and treatment of pregnant women:}

- All pregnant women should be screened for $N$ gonorrhoeae and C trachomatis infections at the first prenatal visit.

- Those who are infected should be treated during pregnancy, tested after treatment to ensure therapeutic success and tested again in the third trimester or, failing that, at time of delivery. Their partners should also be treated. Women who test negative but are at risk for acquiring infection later in pregnancy should be screened again in the third trimester. $(2,7,28,33)$ Rescreening for $N$ gonorrhoeae, $C$ trachomatis and other STIs should be considered in the third trimester for women who are not in a stable monogamous relationship.

- Processes should be in place to ensure communication between physicians and others caring for a woman during pregnancy, and those who will care for her newborn. Information regarding maternal STI screening, treatment and risk factors is crucial to the well-being of the newborn, and must be available to all health care providers caring for the newborn at and following delivery.

- Pregnant women who were not screened during pregnancy should be screened for $\mathrm{N}$ gonorrhoeae and $\mathrm{C}$ trachomatis at delivery, using the most rapid tests available. $(7,28)$

\section{Managing newborns exposed to $\mathrm{N}$ gonorrhoeae:}

- A system should be established to ensure that all infants born to mothers found to have untreated $N$ gonorrhoeae infection at delivery are treated.

- If the mother's test results are not available at discharge, a plan must be in place to ensure that she can be contacted promptly if the results are positive. The mother must also be advised to watch her infant for eye discharge in the first week of life and told whom to contact immediately if this symptom develops, or if the child is unwell in any way. When there is doubt about maternal compliance with this recommendation and the mother is considered to be at risk for gonococcal infection, administering one dose of ceftriaxone should be considered for the infant before discharge. 
- Infants born to women with untreated $N$ gonorrhoeae infection at the time of delivery, including those born by Caesarian section,(34) should be tested and treated immediately without waiting for test results.(28)

- Infants exposed to $N$ gonorrhoeae who appear to be healthy at birth, both term and preterm, should have a conjunctival culture for $N$ gonorrhoeae and receive a single dose of ceftriaxone $(50 \mathrm{mg} / \mathrm{kg}$ to a maximum of $125 \mathrm{mg}$ ) intravenously or intramuscularly. The preferred diluent for intramuscular ceftriaxone is $1 \%$ lidocaine without epinephrine $(0.45 \mathrm{~mL} / 125 \mathrm{mg})$. This intervention is both safe and effective. Biliary stasis from ceftriaxone is not considered to be a risk with a single dose. (Ceftriaxone is contraindicated in newborns receiving intravenous calcium. A single dose of cefotaxime [100 mg/kg given intravenously or intramuscularly] is an acceptable alternative.)

- If the exposed infant is unwell in any way, blood and cerebrospinal fluid cultures should also be performed. Infants with established gonococcal disease require additional investigation and therapy in consultation with a specialist in paediatric infectious diseases. $(2,7,28)$

\section{REFERENCES}

1. Canadian Paediatric Society, Infectious Diseases and Immunization Committee. Recommendations for the prevention of neonatal ophthalmia. Paediatr Child Health 2002;7(7):480-3.

2. American Academy of Pediatrics. Prevention of neonatal ophthalmia. In: Pickering LK, Baker CJ, Kimberlin DW, Long SS, eds. Red Book: 2012 Report of the Committee on Infectious Diseases, 29th ed. Elk Grove Village, IL. American Academy of Pediatrics, 2012:880-2.

3. Laga M, Plummer FA, Nzanze H, et al. Epidemiology of ophthalmia neonatorum in Kenya. Lancet 1986;2(8516):1145-9.

4. Galega FP, Heymann DL, Nasah BT. Gonococcal ophthalmia neonatorum: The case for prophylaxis in tropical Africa. Bull World Health Organ 1984;62(1):95-8

5. Davidson HH, Hill JH, Eastman NJ. Penicillin in the prophylaxis of ophthalmia neonatorum. J Am Med Assoc 1951;145(14):1052-5.

6. Forbes GB, Forbes GM. Silver nitrate and the eye of the newborn. Credé's contribution to preventive medicine. Am J Dis Child 1971;121(1):1-3

7. U.S. Centers for Disease Control and Prevention. Sexually transmitted diseases treatment guidelines, 2010. MMWR 2010;59(No. RR-12): www.cdc.gov/std/treatment/2010/default.htm (Accessed November 27, 2014).

8. Nishida H, Risenberg HM. Silver nitrate ophthalmic solution and chemical conjunctivities. Pediatrics 1975;56(3):368-73.

9. Butterheld PM, Emdh RN, Svejda MJ. Does the early application of silver nitrate impair maternal attachment? Pediatrics 1981;67(5):737-8.

10. Laga M, Plummer FA, Piot P, et al. Prophylaxis of gonococcal and chlamydial ophthalmia neonatorum. A comparison of silver nitrate and tetracycline. N Engl J Med 1988;318(11):653-7.

11. Public Health Agency of Canada, National Microbiology Laboratory. National surveillance of antimicrobial susceptibilities of Neisseria gonorrhoeae. Annual Summary 2012: http://publications. gc.ca/collections/collection_2014/aspc-phac/HP57-3-2012-eng.pdf (Accessed November 27, 2014).

12. Isenberg SJ, Apt L, Wood M. A controlled trial of povidone-iodine as prophylaxis against ophthalmia neonatorum. $\mathrm{N}$ Engl J Med 1995;332(9):562-6.

13. Ali Z, Khadije D, Elahe A, Mohammad M, Fateme Z, Narges Z. Prophylaxis of ophthalmia neonatorum comparison of betadine, erythromycin and no prophylaxis. J Trop Pediatr 2007; 53(6):388-92.

14. Ramirez-Ortiz MA, Rodriguez-Almaraz M, Ochoa-Diazlopez H, Diaz-Prieto P, Rodriguez-Suárez RS. Randomised equivalency trial comparing $2.5 \%$ povidone-iodine drops and ophthalmic chloramphenicol for preventing neonatal conjunctivitis in a trachoma endemic area in southern Mexico. Br J Ophthalmol 2007;91(11):1430-4.

15. David M, Rumelt S, Weintraub Z. Efficacy comparison between povidone iodine $2.5 \%$ and tretracycline $1 \%$ in prevention of ophthalmia neonatorum. Ophthalmology 2011;118(7):1454-8.

\section{Managing newborns exposed to C trachomatis:}

- Infants born either vaginally or by Caesarian section to mothers with an untreated chlamydia infection should be closely monitored for symptoms (eg, conjunctivitis, pneumonitis) and treated if infection occurs. $(2,7,28)$ Routine cultures should not be performed on asymptomatic infants.

- Prophylaxis of exposed newborns is not recommended because of the association of macrolides with pyloric stenosis, but may be considered when infant follow-up cannot be guaranteed. $(7,28)$

ACKNOWLEDGEMENTS: This statement has been reviewed by the Community Paediatrics and Fetus and Newborn Committees of the Canadian Paediatric Society, as well as by the Public Health Agency of Canada's Canadian STI Guidelines Expert Working Group and representatives from the Society of Obstetricians and Gynaecologists of Canada.

16. Binenbaum G, Bruno CJ, Forbes BJ, et al. Periocular ulcerative dermatitis associated with gentamicin ointment prophylaxis in newborns. J Pediatr 2010;156(2):320-1.

17. Nathawad R, Mendez H, Ahmad A, et al. Severe ocular reactions after neonatal ocular prophylaxis with gentamicin ophthalmic ointment. Pediatr Infect Dis J 2011;30(2):175-6.

18. Darling EK, McDonald H. A meta-analysis of the efficacy of ocular prophylactic agents used for the prevention of gonococcal and chlamydial ophthalmia neonatorum. J Midwifery Womens Health 2010;55(4):319-27.

19. Gray J. Executive Director, Canadian Medical Protective Agency. June 2013. Personal communication.

20. Wong T. Director, Professional Guidelines and Public Health Practice Division, Centre for Communicable Diseases and Infection Control, Public Health Agency of Canada. June 2013, Personal communication.

21. Hammerschlag MR. Chlamydial and gonococcal infections in infants and children. Clin Infect Dis 2011;53(Suppl 3):S99-102.

22. Rettig PJ, Patamasucon P, Siegal JD. Postnatal prophylaxis of chlamydial conjunctivitis. JAMA 1981;246(20):2321-2.

23. Bell TA, Sandström KI, Gravett MG, et al. Comparison of ophthalmic silver nitrate solution and erythromycin ointment for prevention of natally acquired Chlamydia trachomatis. Sex Transm Dis 1987;14(4):195-200.

24. Chen JY. Prophylaxis of ophthalmia neonatorum: Comparison of silver nitrate, tetracycline, erythromycin and no prophylaxis. Pediatr Infect Dis J 1992;11(12):1026-30.

25. Hammerschlag MR, Cummings C, Roblin PM, Williams TH, Delke I. Efficacy of neonatal ocular prophylaxis for the prevention of chlamydial and gonococcal conjunctivitis. N Engl J Med 1989;320(12):769-72.

26. Black-Payne C, Bocchini JA Jr, Cedotal C. Failure of erythromycin ointment for postnatal ocular prophylaxis of chlamydial conjunctivitis. Pediatr Infect Dis J 1989;8(8):491-5.

27. Rosenman MB, Mahon BE, Downs SM, Kleiman MB. Oral erythromycin prophylaxis vs watchful waiting in caring for newborns exposed to Chlamydia trachomatis. Arch Pediatr Adolesc Med 2003;157(6):565-71.

28. Public Health Agency of Canada, Centre for Communicable Diseases and Infection Control. Canadian guidelines on sexually transmitted infections: The evergreen edition. Updated January 2010: www.phac-aspc.gc.ca/std-mts/sti-its/guide-lignesdir-eng.php (Accessed November 27, 2014).

29. Public Health Agency of Canada. Notifiable Diseases On-Line. Gonococcal ophthalmia neonatorum. Number of Reported Cases, Canada, 1990 to 1999: http://dsol-smed.phac-aspc.gc.ca/dsol-smed/ ndis/disease2/gon-eng.php (Accessed November 27, 2014).

30. Public Health Agency of Canada. Notifiable Diseases On-Line: http://dsol-smed.phac-aspc.gc.ca/dsol-smed/ndis/charts.php?c=gb (Accessed November 27, 2014). 
31. Alberta Health Services, Centralized STI Services, February 2014, personal communication.

32. Laga M, Meheus A, Piot P. Epidemiology and control of gonococcal ophthalmia neonatorum. Bull World Health Organ 1989;67(5):471-8.

33. Public Health Agency of Canada. Canadian guidelines on sexually transmitted infections. Supplementary statement for recommendations related to the diagnosis, management, and followup of pregnant women. March 2014: www.phac-aspc.gc.ca/std-mts/stiits/cgsti-ldcits/preg-ence-eng.php (Accessed November 27, 2014).

34. Diener B. Cesarean section complicated by gonococcal ophthalmia neonatorum. J Fam Pract 1981;13(5):739-44.

\section{CPS INFECTIOUS DISEASES AND IMMUNIZATION COMMITTEE}

Members: Natalie A Bridger MD; Jane C Finlay MD (past member); Susanna Martin MD (Board Representative); Jane C McDonald MD; Heather Onyett MD; Joan L Robinson MD (Chair); Marina I Salvadori MD (past member); Otto G Vanderkooi MD

Liaisons: Upton D Allen MBBS, Canadian Pediatric AIDS Research Group; Michael Brady MD, Committee on Infectious Diseases, American Academy of Pediatrics; Charles PS Hui MD, Committee to Advise on Tropical Medicine and Travel (CATMAT), Public Health Agency of Canada; Nicole Le Saux MD, Immunization Monitoring Program, ACTive (IMPACT); Dorothy L Moore MD, National Advisory Committee on Immunization (NACI); Nancy ScottThomas MD, College of Family Physicians of Canada; John S Spika MD, Public Health Agency of Canada

Consultant: Noni E MacDonald MD

Principal authors: Dorothy L Moore MD, Noni E MacDonald MD

The recommendations in this statement do not indicate an exclusive course of treatment or procedure to be followed. Variations, taking into account individual circumstances, may be appropriate. All Canadian Paediatric Society position statements and practice points are reviewed on a regular basis. Retired statements are removed from the website. Please consult the Position Statements section of the CPS website (www.cps.ca) for the full-text, current version. 


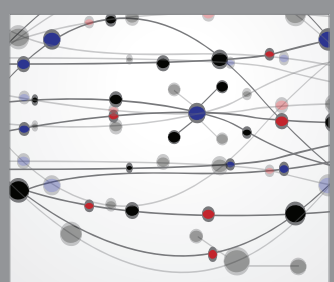

The Scientific World Journal
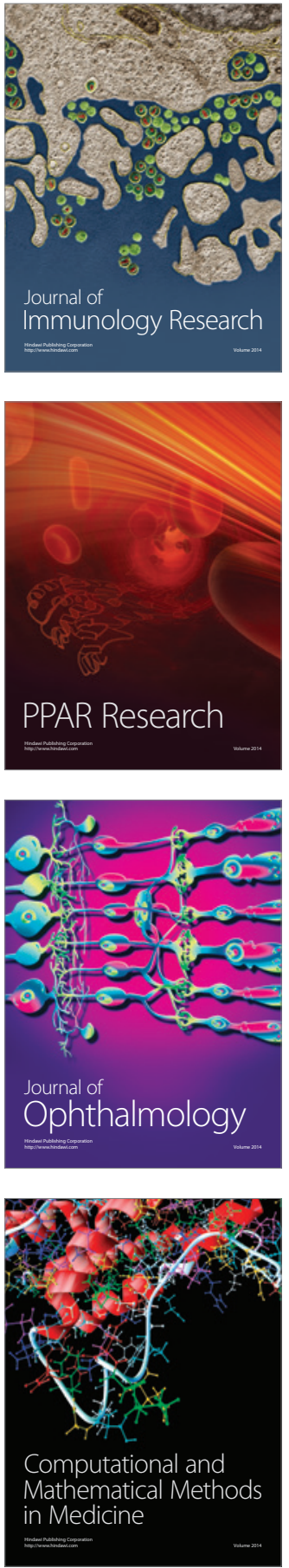

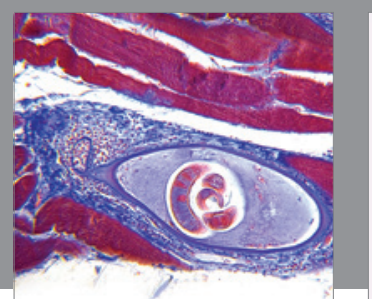

Gastroenterology Research and Practice

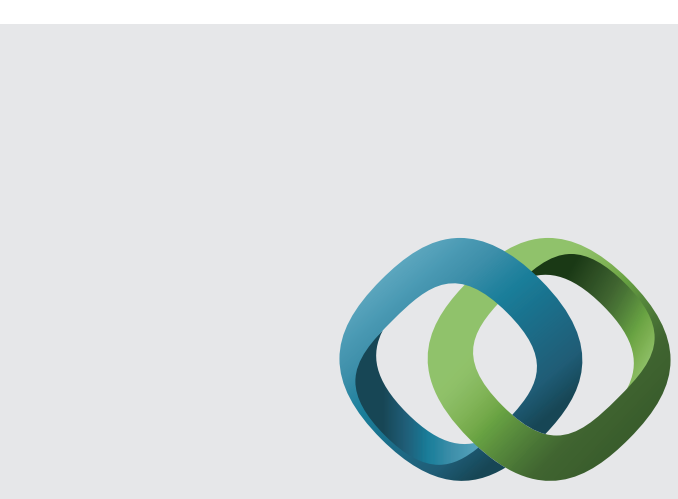

\section{Hindawi}

Submit your manuscripts at

http://www.hindawi.com
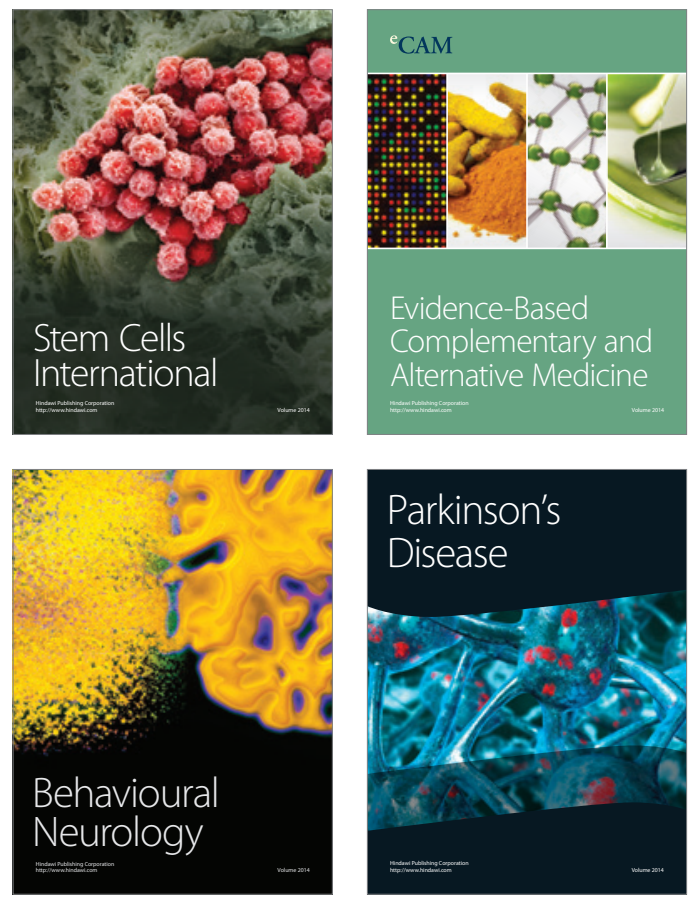
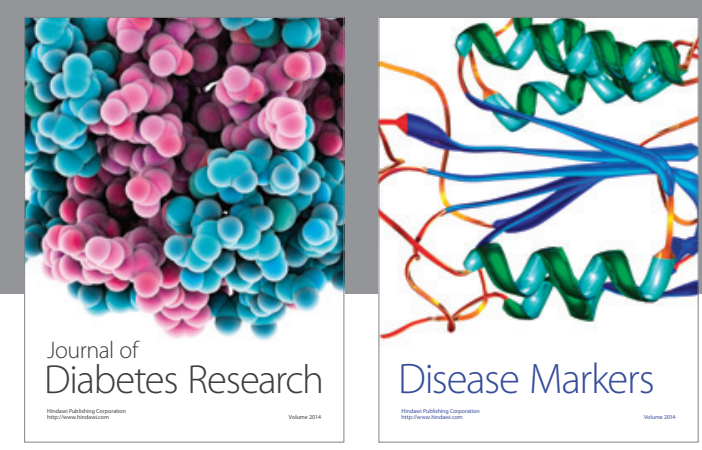

Disease Markers
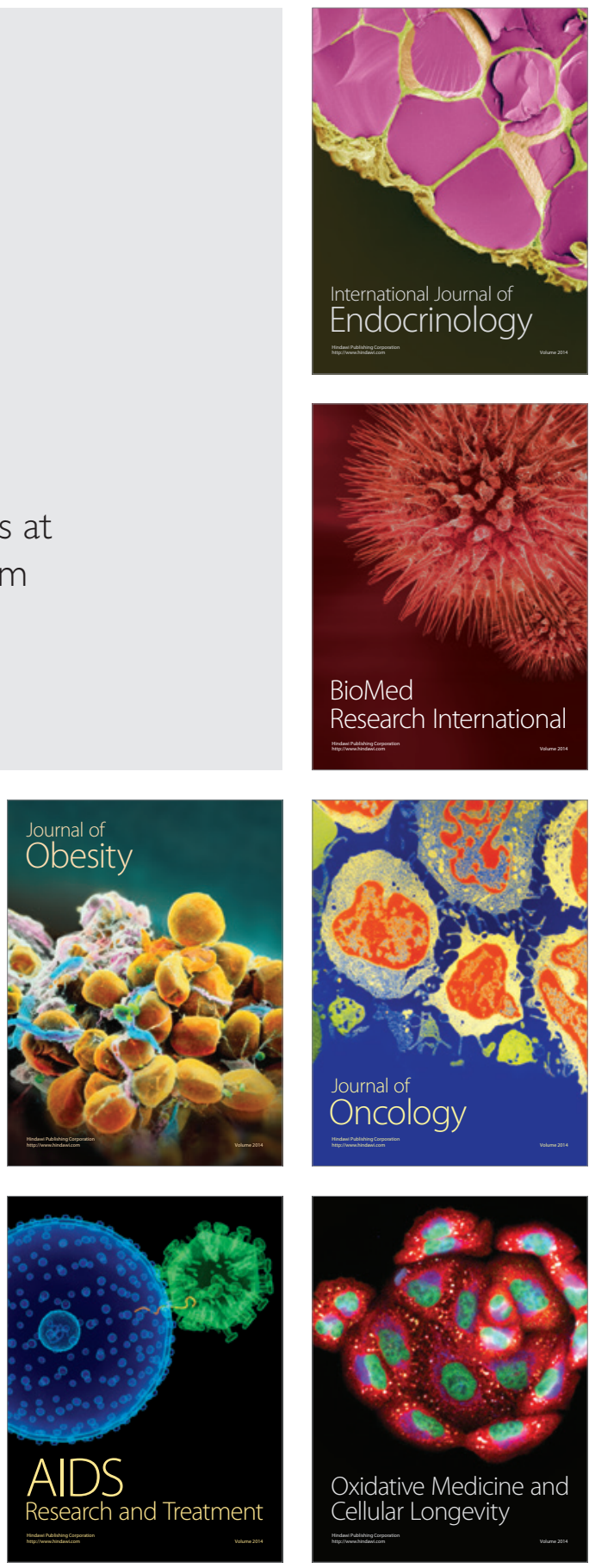